\title{
A Study of Savings of Power Consumption and Server Space through Integrated Virtualization of UNIX Servers
}

\author{
Lee Yong Hui ${ }^{1}$ and Kim Hwan Seok ${ }^{2}$ \\ ${ }^{1}$ Shinsung University, Chief of Information Service Center, \\ DaehackRo1 Jungmimyun, DanginCity, ChungNam, 343-861, Korea \\ ${ }^{2}$ Gangneung-Wonju National University, Dept. Information and \\ Telecommunication Engineering, 220-711, Korea \\ lyhkpi@shinsung.ac.kr,hskim8805@gwnu.ac.kr \\ Abstract
}

As new servers have been introduced and installed or computer room which already has various servers, many problems, such as a lack of room space, alock of rack space, and a rise in power consumption, have arisen. The increasing number of operators and rising cost of maintenance caused by the problems leadinto a rise in 15 expenditure for the computer room. To solve the problems, server integration \& virtualization technology, which is used to save power consumption and space and reduce maintenance cost, has gradually been expanding. In this paper, old six WNIX servers Were integrated into two in the virtualization process of UNIX servers, in which one partition (DLPAR) per server was created, and more than three DB instances were generated in the created partition for DBMS. As a result, multiple physical servers were made as integrated virtualization servers which ended up solving the space problem in a compltter room, securing a rack space and increasing the efficiency of a thermo-hygrostat. More specifically, the server integration \& virtualization process brought about the following saving rates: $72 \%$ of rack space $(U)$ in a computer room, $90 \%$ of power W), and $59 \%$ of cooling (BTU).

Keywords: server integration \& virtualization, DLPAR, UNIX server

\section{Introduction}

As of now, servers in a computer room run in an independent $\mathrm{H} / \mathrm{W}$ type in order to minimize interference from each other by service. However, the introduction of new H/W systems causes lacks of room space and rack space and rises in power consumption, introduction cost and maintenance cost. Now over $70 \%$ of IT expenditure is spent for maintenanee, and only less than $30 \%$ of it is used for improvement and enhancement of competitiveness. To solve the problem, it is necessary to build a dynamic and flexible work infrastructure through virtualization of all IT assets and thus to implement cloud virtualization [1-3] of desktop PCs to data centers. Virtualization technology is used to show actual physical resources as logical resources, so that physical resources are displayed as logical types to their users. In other words, virtualization technology serves the function of connecting actual physical resources with logical resources. In the technology, the middle layer of virtualization is used to separate applications and services from actual resources so that users can share the same resources and use IT resources as a pool of logical resources rather than individual resources. A case in point of the virtualization technology is partitioning in a server, a technique which virtually makes a large server system as multiple small systems to share server resources. Switching to a virtualization system produces some gains: the first is 
reductions in operation cost of a data center and the cost of a new investment; the second one is the efficiency of manpower regarding the time required by repetitive work processes; the third one is to realize Green-IT through low-power consumption operation made by improvements in power, constant temperature \& humidity, and rack space. In this paper, old six UNIX servers were integrated into two in the virtualization process of UNIX servers, in which one partition (DLPAR) per server was created, and more than three DB instances were generated in the created partition for DBMS [11].

\section{Sever Virtualization Technology}

Virtualization technology began with the virtual memory of mainframe in the late $1960 \mathrm{~s}$. Since then, virtual storage, physical partitioning, and hypervisor technology to support dynamic partitions have been launched in the IT market. Like this, new virtualization technologies led by in mainframe have been introduced step by step in many fields. It is fair to say that the history of server virtualization is the history of mainframe which had led virtualization technology. Virtualization has four basic functions for resources: Sharing, Aggregation, Emulation, and Insulation. With regard to server virtualization, it is necessary to understand the techniques described below, which are-basic theories for server virtualization. Based on the techniques, an integrated virtualizafion server [4-6] is established.

\subsection{Virtualization Effect}

Virtualization benefits can vary as per the potential virtualization user goals or their approach methods, adopted technology and the existing IT infrastructure types. Most users can have the benefits mentioned below 1) $\sim 84$ even when simply using the server integrated virtualization. Also, when the users make more efforts in their IT infrastructure virtualization, the potential virtualization benefits can be attained as well with corresponding rate. The potential benefits that can be attained in inducing the virtualization are as follows:

1) Higher utilization rate in the resources: virtualization enables the active sharing for the physical esources and the resources pool, through which the utilization rates of the higher resourdes can be achieved. Especially, in the variable work load situations with the average work load that is much less than the overall resources work load, the higher effects can be expected.

2) Lower management cost : virtualization improves management resources' productivity by reducing the number of the physical resources that have to be managed. physical resources' complexity reduction simplify the common management tasks through the automation, informationization and centralization enables the automation in the work load nanagement Also, virtualization allows the management tools function in the species platform environment as well.

3) U, Sability : virtualization allows the resources to be dynamically reorganized and utilized to meet the business needs in the fast paced work environment.

4) Improved security : virtualization allows the separation that isn't achieved easily in the simple sharing mechanism for the data and services and provide safe access.

5) High fusibility : virtualization supports the removal, upgrading, or changing the physical resources without influencing the user level. Increased expandability : resource LPARs and Aggregation enable the virtualized resources to become smaller or bigger than each of the physical resources, through which the proper expandability can be achieved with no change in the physical resources. 
6) Interoperability and investment protection : virtualization resources offer compatibility of the interface in the protocol level that can't be achieved among the existing physical resources.

7) Improved provisioning : virtualization enables the resources allotment within the more detailed part units rather than in the individual physical unit.

\subsection{Virtual Machine}

Server virtualization using Virtual Machine [7-8, 12] is also called software partitioning or OS image virtualization. Here virtual machine is a sort of a simplified and transformed parent OS, over which well-known full operating systems, such as Linux and Windows, are installed. An individual OS image running over a virtual machine can access actual devices and emulated devices.

\subsection{Pre-examination Conditions for Server Integration}

The technology of integrated virtualization seryer is investigated to save the operating expenditure caused by replacement of old systems and introduction of new equipment [9-10, 13]. As of now, virtualization technology is used to reduce the number of physical servers through the integration of servers for office work and thus save the maintenance cost in a digital data center (security of rack space and a fall in power consumption) and reduce the complexity of infrastructure. Therefore, it is necessary to thoroughly investigate the actual conditions of each server's operating environment and use resources to choose a proper integration server; to thoroughly 1ookinto compenents for duplication and storage devices to prepare for failures before estabirshing the integrated virtualization servers.

1) The analysis of servers operating environments and states.

2) Choice of the servers to be virtualized (systems with old equipment, H/W failures, and hard-to-supply parts, systems with low specifications, and large systems which consumes power a lot against their use rates and occupy much rack space in a computer room.)

3) Choice of integrated virtualization servers (the specifications and quantity of integrated servers are chosengater each server's purpose, OS, and H/W resources including CPU, Memory, and Disk are examined, and the future extensibility is taken into account.)

4) Establishment of integrated virtualization servers (established is virtualization measurers against simultaneous service stop of integrated virtualization systems when H/W failure or network failure occurs.)

\section{Establishment of Integrated Virtualization Servers with UNIX System}

\section{1. $\mathrm{H} / \mathrm{W}$ and $\mathrm{S} / \mathrm{W}$ for Integrated Virtualization}

$83.3 \%$ of $\mathrm{H} / \mathrm{W}$ devices for integrated virtualization have been used for more than five years since their introduction. Therefore, the old devices need to be replaced and have low extensibility and efficiency, as shown in Table 1. According to the monitoring of server operation at ordinary times, CPU use rate was less than $30 \%$, and the number of users have access at the same time was lower than 10. The server to be integrated is a database (DB) server running separately. As shown in Table 1, DBMS in use is Oracle Database Version9 or $10 \mathrm{~g}$. Data are saved into a local disk or a storage device. The file system in use is UFS, and open S/W applications such as Apache and Tomcat are running. 
Table 1. Components of $\mathrm{H} / \mathrm{W}$ and $\mathrm{S} / \mathrm{W}$

\begin{tabular}{|c|c|c|c|c|c|c|c|c|}
\hline \multirow{2}{*}{ No. } & \multirow{2}{*}{ Sever } & \multirow{2}{*}{ Model } & \multicolumn{2}{|l|}{ CPU } & \multirow{2}{*}{$\begin{array}{l}\text { Memory } \\
\text { (MB) }\end{array}$} & \multirow{2}{*}{$\begin{array}{l}\text { Disk } \\
\text { (GB) }\end{array}$} & \multirow{2}{*}{ os } & \multirow{2}{*}{ SW } \\
\hline & & & Model & core & & & & \\
\hline 1 & A & SUN B6000 & $\begin{array}{c}\text { U.SPARC-T2 } \\
1.2 \mathrm{GHz}\end{array}$ & 2 & 8192 & 146 & $\begin{array}{c}\text { Solaris } \\
10\end{array}$ & $\begin{array}{c}\text { Oracle } \\
10 \mathrm{~g}\end{array}$ \\
\hline 2 & $\mathrm{~B}$ & SUN SF48OR & $\begin{array}{l}\text { U.SPARC-III } \\
1.2 \mathrm{GHz}\end{array}$ & 2 & 4096 & 128 & $\begin{array}{c}\text { Solaris } \\
9\end{array}$ & $\begin{array}{c}\text { Oracle } \\
9 i\end{array}$ \\
\hline 3 & c & SUN SF490 & $\begin{array}{l}\text { U.SPARC-IV } \\
+1.5 \mathrm{GHz}\end{array}$ & 2 & 8192 & 1024 & $\begin{array}{c}\text { Solaris } \\
10\end{array}$ & $\begin{array}{c}\text { Oracle } \\
9 i\end{array}$ \\
\hline 4 & $D$ & SUN SF48OR & $\begin{array}{c}\text { U. ZPARC-III } \\
1.2 \mathrm{GHZ}\end{array}$ & 2 & 4096 & 72 & $\begin{array}{c}\text { Solaris } \\
2.9\end{array}$ & $\begin{array}{c}\text { Oracle } \\
9 i\end{array}$ \\
\hline 5 & E & SUN SF880 & $\begin{array}{l}\text { U.SPARC-III } \\
1.2 \mathrm{GHz}\end{array}$ & 4 & 8192 & 1024 & $\begin{array}{c}\text { Solaris } \\
9\end{array}$ & $\begin{array}{c}\text { Oracle } \\
9^{\bullet}\end{array}$ \\
\hline \multirow[t]{2}{*}{6} & $\mathrm{~F}$ & SUN SF880 & $\begin{array}{l}\text { U.SPARC-III } \\
\text { 1.2GHz }\end{array}$ & 4 & 4096 & 300 & & \\
\hline & \multicolumn{3}{|c|}{ Total } & 16 & 36864 & 2694 & & \\
\hline
\end{tabular}

3.2. Matters to be taken into Account from the Analysis of Actual Conditions

1) $\mathrm{H} / \mathrm{W}$ matters

In the case of transferring the $\mathrm{H} / \mathrm{W}$ and $\mathrm{OS}$ of a single manufacturer, compatibility should be taken into account. Database with a low use rate and importance needs to be taken into account for DB integration

2) $\mathrm{S} / \mathrm{W}$ matters

In the case of different kinds of 0 ss and File Systems, the ways and speeds to transfer data to a target system should be taken into account. And, compatibility with the existing operating enviromment should be taken into consideration to make the optimal operating enyironment.

\subsection{The Result of the Establishment of UNIX Virtualization Servers}

Various kinds of Virtualization technology including DLPAR, VIO, Micro-Partition, and Shared Processor/Memory were applied to the target system. IBM PowerVM was applied to DB servers. VIO-Server was made to apply duplication (HA) and future extension and thus enhance the efficiency of resources. Also, as shown in Table 2, the six UNIX servers were integrated into UNIX servers by the application of the partition virtualization technology of each server manufacturer. One partition per server (DLPAR applied) was created, and more than three $\mathrm{DB}$ / Instances were generated in the created partition for DBMS. PowerHA Solution which the manufacturer of the integrated servers provides was used to build highavailability System which is capable of taking over a failure to a stand-by server. As a result, the server integration and virtualization process ended up saving $72 \%$ of rack space $(\mathrm{U})$ of the UNIX system in a computer room, $90 \%$ of power (W), and $59 \%$ of cooling (BTU), as shown in Tabie 3.

Table 2. SPECS of Two Integrated Servers

\begin{tabular}{|c|c|c|c|c|c|}
\hline $\begin{array}{c}\text { Virtual } \\
\text { Consolidate }\end{array}$ & CPU & Memory & HDD & NIC & HBA \\
\hline Server \#1 & 64bit, $3.3 \mathrm{GHz}, * 12$ core & $64 \mathrm{~GB}$ & $300 \mathrm{~GB} * 8 \mathrm{EA}$ & 8 & 16 \\
\hline Server \#2 & $64 \mathrm{bit}, 3.3 \mathrm{GHz}, * 12$ core & $64 \mathrm{~GB}$ & $300 \mathrm{~GB} * 8 \mathrm{EA}$ & 8 & 16 \\
\hline
\end{tabular}


Table 3. Comparison of Rack Space, Power Consumption and Cooling Saving after Integrated Virtualization

\begin{tabular}{|c|r|r|r|r|c|}
\hline \multirow{2}{*}{ Items } & \multicolumn{2}{|c|}{ Before } & \multicolumn{2}{c|}{ After } & \multirow{2}{*}{ Saving rate } \\
\cline { 2 - 5 } & Quantity & Cost(\$) & Quantity & Cost(\$) & \\
\hline Upper space (U) & 53 & 15,462 & 16 & 4,258 & $72 \%$ \\
\hline Power consumption (W) & 14,762 & 8,875 & 2,856 & 887 & $90 \%$ \\
\hline Cooling(BTU) & 12,166 & 563 & 9,760 & 233 & $59 \%$ \\
\hline
\end{tabular}

\section{Conclusion}

In this paper, old six UNIX servers were integrated into two in the virtualization process of UNIX servers, in which one partition (DLPAR) per server was created, and more than three DB instances were generated in the created partition for DBMS. The server integration and virtualization process helped saved $72 \%$ of rack space $(U)$ in a computer room, $90 \%$ of power (W), and 59\% of cooling (BTU). The server integration and virtualization is expected to help save the maintenance cost in a computer room and realize Green-IT.

\section{References}

[1] M. Carlson, M. "Systems and Xirtualization Management: Standards and the Cloud" (A report on SVM 2012) (journal of network and systems management. [SCIE, SCOPUS], vol. 21, no. 3, (2013).

[2] H. Lv, Y. Dong, J. Duan and K. Tian, "Virtualization Challenges: A View from Server Consolidation Perspective", (ACM SIGPI/AN Notices), [SCIE, SCOPUS], vol. 47, no. 7, (2012).

[3] Y. Zhan, "Virtualization and Cloud Computing," LECTURE NOTES IN ELECTRICAL ENGINEERING, vol. 143, 2012.

[4] B. Solomon, D. Ionescu, M. Litolu and M Mihaescu, "Web Service Distributed Management Framework for Autonomic Server Virtualization," COMMUNICATIONS IN COMPUTER AND INFORMATION SCIENCE, vol. 18, (2008)

[5] H. Ueno, S. Hasegawa and 1. Hasegawa, "Virtage: Server Virtualization with Hardware Transparency," Lecture Notes in Computer Science, vol.- no. 6043, (2010).

[6] D. Paessler, "Server Virtualization and Network Management," Database and network journal, vol. 38, no. 5, (2008).

[7] C. Taylor, "Server Consolidation: How to enhance utilization of servers and storage," MANUFACTURING COMPUTER SOLUTIONS, vol. 12, no. 5, (2006).

[8] A. Kadir X Xu and E. Hammerle, "Virtual machine tools and virtual machining-A technological review," Robotics and computer-integrated manufacturing, vol. 27, no. 3, (2011).

[9] S.J. Schychart, "Server Consolidation: Why Less Is More Is your data center a morass of disparate hardware and operating system installs?" NETWORK COMPUTING -MANHASSET, vol. 14, no. 11, (2003).

[10] K. Henry, "Server Consolidation: cost saving but what about security?" Database and network journal, vol. 32, no. 2, (2002).

[11] L. Y. Hui and K. H. Seok, "A Study on UNIX Server Consolidation Virtualization (Advanced Science and Technology Letters", (Mobile and Wireless), vol. 42, (2014), pp. 43-47.

[12] T. Koju, S. Takada and N. Doi, "An Efficient and Generic Reversible Debugger using the Virtual Machine based Approach," VEE -INTERNATIONAL CONFERENCE, vol. 1, (2005).

[13] Y. Ding, "Server Consolidation and Grid Computing: Performance Implications," CMG CONFERENCE, vol. 1 , no. 1, (2003). 


\section{Authors}

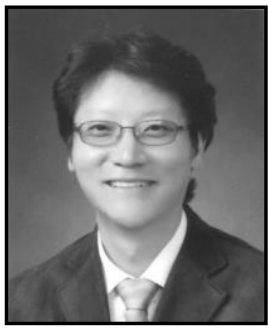

Lee Yong Hui, he received his $\mathrm{BS}, \mathrm{MS}$ and $\mathrm{PhD}$ in Electronic Engineering from CheongJu University, CheongJu, Rep. of Korea, in 1989, 1991 and 2001, respectively. He worked at HYNIX Semiconductor ULSI LAB from 1995 to 2002. Since 2002, he has been dept, of Computer Application and Chief of Information Service Center at Shinsung University, Dangin, Rep. of Korea. His current research interests include computer control, microprocessor, web programming, RFID, server, network and information security.

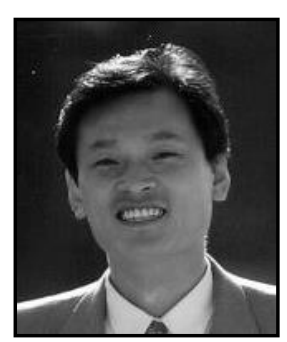

Kim Hwan Seok, he received his BS, MS and PhD in Electronic Engineering from CheongJu University, CheongJa, Rep. of Korea, in 1988, 1990 and 2008, respectively Since 1992, he has been dept, of Information and Telecommunication Engineermg, Gangneung-Wonju National University, WonJU, Rep. of Korea) His current research interests include VLSI and CAD, smart product, smart healthcare and application programming

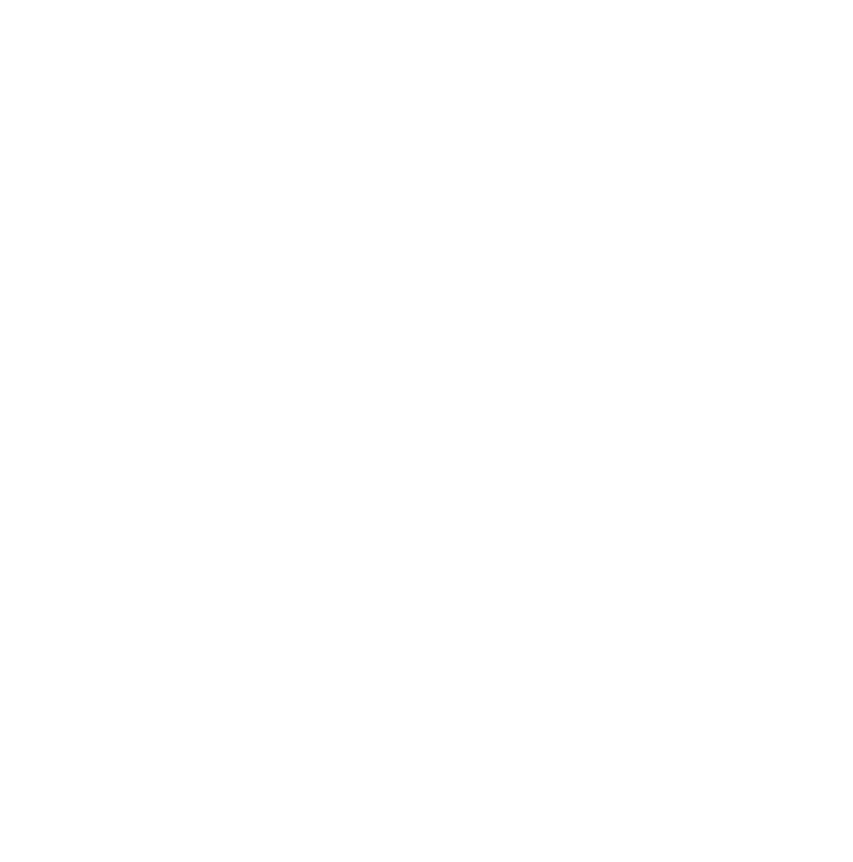

